\title{
Difficulties in emotion regulation and psychopathic traits in violent offenders
}

\author{
Carlo Garofalo $^{\mathrm{a}, *}$, Craig S. Neumann ${ }^{\mathrm{b}}$, Patrizia Velotti ${ }^{\mathrm{c}}$ \\ a Department of Developmental Psychology, Tilburg University, The Netherlands \\ b Department of Psychology, University of North Texas, Denton, (TX), United States \\ ${ }^{\mathrm{c}}$ Department of Educational Sciences, University of Genoa, Italy
}

\section{A R T I C L E I N F O}

\section{Keywords:}

Psychopathy

Emotion dysregulation

Offenders

Latent profile analysis (LPA)

Structural equation modeling (SEM)

\begin{abstract}
A B S T R A C T
Purpose: The present study aimed to advance our understanding of the relevance of emotion dysregulation (ED) for psychopathy.

Methods: Latent Profile Analysis (LPA) and Structural Equation Modeling (SEM) were employed to examine person- and variable-centered associations between ED domains and psychopathic traits in a moderately-large $(N=268)$ sample of violent male offenders.

Results: LPA results indicated a 3-class solution with offenders most accurately classified based on ED levels (low, medium, high) across domains. The three ED subgroups revealed linear positive associations with psychopathy total, affective, and lifestyle facet scores, such that elevated levels of these traits were found in subgroups with greater ED. A similar linear trend emerged for the antisocial - but not interpersonal - facet, in-line with recent studies showing positive associations between executive functioning and interpersonal features of psychopathy. In SEM analyses, a latent ED factor positively predicted a super-ordinate psychopathy factor, controlling for psychopathological distress.

Conclusions: Taken together, current findings support the notion that ED involves broad difficulties across emotion regulation domains, which vary by degree rather than in kind, and that these difficulties have linear positive relations with psychopathic traits among violent offenders.
\end{abstract}

\section{Introduction}

Psychopathic personality is characterized by early-onset and persistent behavioral deviance in the company of a callous and exploitative interpersonal style (Cleckley, 1941/1988; Hare \& Neumann, 2008; Patrick, Fowles, \& Krueger, 2009). For the purpose of this study, we define the multifarious construct of psychopathy in terms of clusters of affective (e.g., callousness), interpersonal (e.g., manipulation), lifestyle (e.g., impulsivity), and antisocial (e.g., poor behavioral control) features (Hare \& Neumann, 2008; Neumann, Hare, \& Pardini, 2015). These four domains combine to form the pathological syndrome of psychopathy as operationalized in the Psychopathy Checklist-Revised (PCL-R; Hare, 2003) and its derivatives (i.e., PCL: Screening Version, PCL: Youth Version, Self-Report Psychopathy scale; Forth, Kosson, \& Forth, Kosson, \& Hare, 2003; Hart, Cox, \& Hare, 1995; Neumann, Hare, \& Newman, 2007; Paulhus, Neumann, \& Hare, 2016).

Many theoretical accounts of psychopathy consider emotional dysfunctions as a central feature of the disorder (Blair, 2005; Cleckley, 1941/1988; Hare \& Neumann, 2008; Kosson, Vitacco, Swogger, \&
Steuerwald, 2016; Lykken, 1995; Patrick et al., 2009). Yet, the extent to which these dysfunctions include problems in emotion regulation is unclear. A deeper understanding of this issue is necessary, as emotion dysregulation may be one of the mechanisms linking psychopathy and aggressive behavior (Davidson, Putnam, \& Larson, 2000; Garofalo, Holden, Zeigler-Hill, \& Velotti, 2016; Hare, 2003; Long, Felton, Lilienfeld, \& Lejuez, 2014; Patrick \& Zempolich, 1998). More broadly, understanding the relevance of emotion regulation for psychopathy may be useful to refine etiological models and treatment approaches, given emotion regulation is shaped throughout the development (Frick \& Morris, 2004; Patrick et al., 2009), and represents a dynamic factor that can be targeted in treatment (Garofalo, Velotti, \& Zavattini, 2017; Roberton, Daffern, \& Bucks, 2015). In the present study, an emotion regulation framework was employed to examine relations between difficulties in emotion regulation domains and psychopathic traits in violent male offenders.

\footnotetext{
* Corresponding author at: Department of Developmental Psychology, Tilburg University, Tilburg, P.O. Box 90153, 5000, LE, The Netherlands.

E-mail address: c.garofalo@uvt.nl (C. Garofalo).
} 


\section{Emotion dysregulation: multiple components, selected impairments?}

An influential and comprehensive operationalization of the construct defines emotion dysregulation as the impairment in one or more of the following domains: awareness, understanding, and acceptance of emotional responses; ability to engage in goal-directed behavior when upset; ability to refrain from impulsive behavior when upset; and ability to engage in effective emotion regulation strategies (Gratz \& Roemer, 2004). ${ }^{1}$ These impairments have been related to psychopathology transdiagnostically, and to personality pathology in particular (Aldao, Nolen-Hoeksema, \& Schweizer, 2010; Carpenter \& Trull, 2013; Dimaggio et al., 2017; Gratz, Rosenthal, Tull, Lejuez, \& Gunderson, 2009; Kring \& Sloan, 2009). The rationale behind a multi-domain conceptualization of emotion regulation was to pinpoint the dissociable nature of these components to identify how specific domains might be related to distinct forms of psychopathology (Gratz \& Roemer, 2004).

However, the preponderance of empirical evidence accumulated so far appears to show that impairments in these domains - at least as assessed via self-report - reflect a general underlying deficit in emotion regulation. Specifically, the emotion regulation dimensions have demonstrated weak discriminant validity, which may indicate that impairments across domains go hand in hand, such that difficulties in emotion regulation vary in degree rather than in kind (for a recent review, see John \& Eng, 2014). Yet, no studies to date have examined this issue from a person-centered perspective; that is, if it is possible to identify subtypes of individuals based on unique emotion dysregulation profiles. Among offenders, identifying different subtypes based on emotion dysregulation domain profiles versus levels could help address whether there are unique versus widespread associations between emotion dysregulation domains and psychopathic traits. In either case, research on this issue could help elucidate the relevance of emotion regulation for psychopathy.

\subsection{Competing views on the links of emotion dysregulation and psychopathic traits}

An early review of historical descriptions of the psychopathic personality found general agreement among scholars in considering emotional instability and low frustration tolerance (both intimately linked to emotion dysregulation; Carpenter \& Trull, 2013) among the defining features of psychopathy (Albert, Brigante, \& Chase, 1959). An explicit reference to a lack of emotional stability remains in the Comprehensive Assessment of Psychopathic Personality (CAPP) model (Cooke, Hart, Logan, \& Michie, 2012), but other contemporary conceptualizations diverge in the emphasis placed on emotion dysregulation in relation to psychopathic traits. Part of the reason might be that a long-held view considered the prototypical psychopath as fundamentally devoid of emotions, hence not requiring emotion regulation (Baskin-Sommers, 2017). Yet, lack of empirical support for a complete absence of emotional experience in psychopathy (Brook, Brieman, \& Kosson, 2013; Derefinko, 2015; Hoppenbrouwers, Bulten, \& Brazil, 2016; Kosson et al., 2016) has led investigators to argue that individuals with

\footnotetext{
${ }^{1}$ For the sake of consistency with the main scope of the present study, we do not address here near-neighbor concepts of emotion regulation, such as emotion generation/ reactivity. We refer readers interested in the relation between emotion generation and regulation to the thorough discussions published in the emotion literature (e.g., Gross \& Barrett, 2011; Tamir, 2011). These insightful writings have clarified how the consideration of emotion generation and regulation as separable entities depends on the commitment to different theoretical schools in emotion research (Gross \& Barrett, 2011), and concluded that most authors would agree that 'emotion regulation can and should be studied, regardless of whether it is viewed as separate from emotion generation' (Tamir, 2011, p. 5). For the purpose of the present study, we therefore refrain from reviewing the vast literature on psychopathy and emotional reactivity or processing, which could bear only indirect relations with the main focus of this investigation (see Garofalo \& Neumann, 2018, for some considerations on this issue).
}

psychopathic traits do feel emotions, but have difficulty regulating them (Baskin-Sommers, Stuppy-Sullivan, \& Buckholtz, 2016; Harenski \& Kiehl, 2010).

A nuanced perspective, based on the response modulation theory of psychopathy, attempted to link specific emotion regulation domains with certain psychopathic features. In particular, the interpersonal-affective traits of psychopathy were hypothetically related to poor attention to emotions (i.e., lack of emotional awareness and clarity), whereas lifestyle-antisocial traits were hypothesized to be related to problems in modulating emotions and behavior when distressed (Malterer, Glass, \& Newman, 2008; Patterson \& Newman, 1993). As mentioned above, however, whether specific components of trait emotion dysregulation are empirically dissociable remains unclear. More recent developments of the theoretical perspective proposed by Newman and collaborators (e.g., the Impaired Integration model; Hamilton, Racer, \& Newman, 2015) have posited that abnormalities in integrative functioning of neural systems - and, in particular, underdeveloped connectivity within emotion-related neural circuitry - would underlie deficits in emotional awareness that characterize psychopathy. In this context, it has been proposed that what is problematic in psychopathy is the lack of initiation of emotional self-regulation, rather than its effectiveness (Vitale \& Newman, 2009).

An alternative perspective, developed in the context of the dualpathway model of psychopathy (Fowles \& Dindo, 2009), proposes that emotion dysregulation may have opposite relations to distinct psychopathic traits. Some scholars have argued that indices of emotion dysregulation are related to behavioral (i.e., antisocial-lifestyle, corresponding to the earlier PCL-R Factor 2) traits of psychopathy because they are associated with externalizing symptoms and general psychological distress. In contrast, the dual-pathway model assumes that emotion dysregulation is not relevant to the interpersonal-affective traits of psychopathy (i.e., PCL-R Factor 1), which were theorized to be associated with intact emotion regulation, largely based on inverse associations between Factor 1 traits and low levels of negative emotionality and internalizing symptoms (Fowles \& Dindo, 2009; Hicks \& Patrick, 2006; Long et al., 2014). ${ }^{2}$

Both these models were based on the earlier two-factor conceptualization of the PCL-R. However, parsing interpersonal and affective traits into separate components, studies have provided emerging evidence for a positive link between affective traits of psychopathy and both negative emotionality (e.g., other-directed negative emotions; Benning, 2013; Benning, Patrick, Hicks, Blonigen, \& Krueger, 2003; Jackson, Neumann, \& Vitacco, 2007; Lishner et al., 2012; Lynam \& Widiger, 2007) and general psychological distress (e.g., anxiety, depression; Colins, Fanti, Salekin, \& Andershed, 2016; Neumann \& Pardini, 2014). Thus, following the arguments of the dual-pathway model, affective features of psychopathy may also be related to greater emotion dysregulation. ${ }^{3}$ Moreover, in the recently developed triarchic model of psychopathy, Patrick et al. (2009) identified difficult temperament - that is, a blend of negative affectivity, poor effortful control and poor emotion regulation - as a developmental precursor of meanness and disinhibition (akin to the affective and behavioral traits of PCL-R-assessed psychopathy, respectively), but not boldness, that

\footnotetext{
${ }^{2}$ This perspective parallels the traditional distinction between primary and secondary psychopathy, whereby secondary psychopathy was related to greater emotional problems, whereas primary psychopathy was not (Karpman, 1948). Yet, this perspective does not come without conceptual challenges, as it appears to confound variable associations with a person-centered approach. Indeed, recent advances in the study of psychopathy subtypes have shown that primary psychopathy is likely characterized by elevations on psychopathic traits that involve both interpersonal-affective, and lifestyle-antisocial features (Neumann et al., 2016).

${ }^{3}$ Importantly, drawing inferences regarding emotion regulation based on findings involving negative emotionality may not be warranted, given that emotion regulation can occur irrespective of extreme levels of negative emotionality, and negative emotionality and emotion regulation can interact in predicting relevant outcomes, including aggression and antisocial behavior (DeLisi \& Vaughn, 2014; Garofalo \& Velotti, 2017).
} 
captures interpersonal functioning. Therefore, based on theory and empirical results, it is reasonable to hypothesize that affective psychopathic traits are related to emotion dysregulation, although it remains unclear if these associations would hold when accounting for general psychological distress. Examining direct links between emotion dysregulation and psychopathic traits, while controlling for the potential confound of psychological distress, is needed to increase precision in our understanding of their relations.

\subsection{Overview of prior studies on emotion dysregulation and psychopathy}

Considering the long-standing tradition of research on emotion regulation and psychopathology in general (Aldao et al., 2010; Kring \& Sloan, 2009), it is surprising that only in the last decade has the study of emotion regulation been applied to psychopathy research. Across different populations and different measures of psychopathy, previous studies have consistently revealed moderate positive associations between emotion dysregulation and higher levels of behavioral psychopathic traits (Ali, Amorim, \& Chamorro-Premuzic, 2009; Donahue, McClure, \& Moon, 2014; Ermer, Kahn, Salovey, \& Kiehl, 2012; Lishner, Swim, Hong, \& Vitacco, 2011; Long et al., 2014; Malterer et al., 2008; Miller et al., 2010; Visser, Bay, Cook, \& Myburgh, 2010), in line with theoretical expectations. ${ }^{4}$ However, only one of these studies had controlled for the influence of negative affect (Donahue et al., 2014), and none of them has ascertained whether these associations could be accounted for by levels of general psychological distress often associated with externalizing psychopathology (which subsumes negative affect and other psychopathological symptoms), as would be predicted by some theoretical perspectives.

Findings involving affective and interpersonal traits of psychopathy have been less consistent, and appear to vary depending on whether psychopathy was assessed with PCL-R-based measures or with the Psychopathic Personality Inventory-Revised (PPI-R; Lilienfeld \& Widows, 2005), and depending on whether interpersonal and affective traits of psychopathy were conflated in one higher-order factor (i.e., Factor 1) or parsed into lower-order factors. Overall, studies examining the broad-band interpersonal-affective factor provided mixed findings. Among PPI-R-based studies, both null or positive associations with better emotion regulation have been found (Donahue et al., 2014; Howe, Falkenbach, \& Massey, 2014; Long et al., 2014; Vidal, Skeem, \& Camp, 2010; Watts et al., 2016), providing some support for the dualpathway model of psychopathy (Fowles \& Dindo, 2009). In contrast, PCL-R-based studies have found evidence of poor emotion regulation (Ermer et al., 2012; Lishner et al., 2011; Malterer et al., 2008; Miller et al., 2010; Visser et al., 2010). In some of these studies, affectiveinterpersonal psychopathic traits were specifically related to poor emotional awareness, and in others there was evidence for widespread emotion dysregulation across domains, providing only partial support for the response-modulation theory (Patterson \& Newman, 1993).

Interestingly, those few studies that focused on narrow-band interpersonal and affective components have provided more consistent evidence across different psychopathy measures, with emotion dysregulation being positively linked to affective traits (i.e., PCL-R affective, and PPI Coldheartedness and Fearlessness), and negatively related or unrelated to interpersonal traits of psychopathy (i.e., PCL-R interpersonal, PPI-R stress immunity and social potency; Donahue et al., 2014; Garofalo, Neumann, \& Kosson, 2017; Vidal et al., 2010). ${ }^{5}$ This

\footnotetext{
${ }^{4}$ These studies have alternatively used the terms emotional intelligence or emotion regulation to refer to (some of) the dimensions of emotion regulation described above. Here, we only use the term emotion regulation for consistency (see Garofalo \& Neumann, 2018 , for a discussion of the jingle-jangle fallacy issues related to the alternative use of the two terms as separate, stand-alone, constructs).

${ }^{5}$ The stress immunity scale is likely a blend of interpersonal and affective traits, at least to the extent it assesses low anxiety. Yet, as it contains items directly tapping good emotion regulation skills, it is not surprising that it shows positive associations with
}

pattern of results is consistent with recent findings that the interpersonal and affective facets of psychopathy show positive and negative associations, respectively, with intelligence and executive functioning (Baskin-Sommers et al., 2015; Salekin, Neumann, Leistico, \& Zalot, 2004; Vitacco, Neumann, \& Wodushek, 2008), since each of these cognitive variables are related to better emotion regulation (Dixon, Thiruchselvam, Todd, \& Christoff, 2017; Watts et al., 2016). In addition, the differential associations that interpersonal and affective traits have with emotion regulation appear consistent with the theoretical premises of the triarchic model, according to which emotion dysregulation may be a developmental precursor of affective (i.e., callousness, meanness), but not interpersonal psychopathic traits (i.e., boldness; Patrick et al., 2009).

\subsection{The present study}

Taken together, prior studies have shown consistent associations between the behavioral features of psychopathy and emotion dysregulation, although it is uncertain whether they mainly reflect general psychological distress. This consideration and the less clear picture concerning the interpersonal and affective traits of psychopathy may contribute to uncertainties regarding the relevance of emotion dysregulation in psychopathy more broadly. Further, previous studies have not provided clear indications as to whether different components of emotion dysregulation can be selectively impaired and differentially related to psychopathic traits. Relatedly, no study to-date has adopted a person-centered perspective to uncover subtypes of individuals based on emotion dysregulation profiles, nor has any study attempted to combine person- and variable-centered methods to test if knowledge at the variable-level translates to findings at the person-level. Thus, additional research that employs both variable and person-centered approaches can significantly increase the precision and depth of information on this topic, while limiting the risk of unwarranted conclusions about individuals based on variable associations.

The present study combined latent person- and variable-centered approaches to examine the multi-domain construct of emotion regulation and its relations to psychopathic traits in violent offenders. In light of the proposed idea that emotion dysregulation components reflect distinct and dissociable processes, we conducted latent profile analyses to test whether subtypes with specific emotion dysregulation profiles could be empirically uncovered. Based on weak findings regarding the discriminant validity of the emotion dysregulation domains that have been examined, we remained agnostic about the possibility of finding unique emotion dysregulation profiles based on different constellations of impairments, as opposed to finding profiles that would differ in severity (across domains) rather than in kind. Next, we validated the LPA subgroups that emerged based on associations with psychopathic traits across domains (i.e., interpersonal, affective, lifestyle, antisocial). When still blind to the LPA results, we hypothesized that we would at least identify a profile of offenders characterized by greater emotion dysregulation, and that this profile would also show higher levels of psychopathic traits. Based on the limited literature, we also expected that more affective features of psychopathy would be evidenced by offenders with greater emotion dysregulation. Finally, to examine the consistency of person- and variable-centered methods, we tested latent variable associations between psychopathic traits and emotion dysregulation, while controlling for psychological distress, again expecting to reveal a significant positive association between emotion dysregulation and psychopathic traits, above and beyond the effect of psychological distress.

(footnote continued)

emotion regulation (Vidal et al., 2010). 


\section{Method}

\subsection{Participants and procedures}

Data were obtained from 268 male violent offenders incarcerated in seven prisons in Northern Italy $\left(M_{\text {age }}=37.36, S D=11.82\right)$. The majority of participants were Italian $(46 \%)$ or from another European country (20\%), whereas the rest of participants were from an African (23\%) or South American country (11\%). All participants were residing in Italy at the time of their offense. As inclusion criteria, all inmates had to be fluent in Italian and had to be convicted of a violent crime (i.e., offenses involving physical violence toward others, such as: aggravated robbery, murder, serious physical assault, sexual offense, and minor repeated physical assaults). ${ }^{6}$ After being informed about the aim of the study, all participants provided their written informed consent and participated without receiving any compensation. Participants were assured that their decisions to participate or decline would not affect their detention status. They were informed that they could withdraw from the study at any time and have their responses removed from the database. The administration of questionnaires was completed in individual or small group sessions that took place in a quiet room where inmates usually meet with prison educators. When possible, the small group sessions were preferred to limit the burden on prison staff members. Two researchers were always present in the room to ensure that participants would fill out the questionnaires independently. Data were collected anonymously and prison staff was not informed about individual scores. The local university Ethics Review Boards and the Italian Ministry of Justice formally approved the study.

\section{Measures}

\subsection{Difficulties in emotion regulation scale (DERS; Gratz \& Roemer, 2004)}

Emotion dysregulation was measured with the DERS, a widely used self-report measure with 36 items rated on a 5-point Likert scale. The DERS was developed to capture difficulties in six interrelated dimensions: nonacceptance of emotional responses (Nonacceptance); difficulties engaging in goal-directed behavior when distressed (Goals); difficulties refraining from impulsive behavior when upset (Impulse); lack of awareness of and attention for emotions (Awareness); limited access to effective emotion regulation strategies (Strategies); and lack of emotional clarity (Clarity). Items are summed to produce scale and total scores, with greater scores indicating greater difficulties in emotion regulation. Prior studies suggest that the DERS total score represents a reliable global index of overall emotion regulation difficulties that shows meaningful associations with physiological, behavioral, and neural indices of emotion regulation (Gratz et al., 2009; John \& Eng, 2014), but the six subscales have shown weak evidence of discriminant validity (John \& Eng, 2014). Both the original version (Gratz \& Roemer, 2004) and its Italian adaptation (Giromini, Velotti, de Campora, Bonalume, \& Zavattini, 2012) have shown adequate psychometric properties, with the partial exception of the Awareness scale, which often shows relatively poorer internal consistency and construct validity (John \& Eng, 2014). Nevertheless, for the present study we opted for keeping in the Awareness scale for continuity with previous research. Internal consistency in the present sample ranged between $\alpha=0.51-0.88$, with mean inter-item correlations ranging between 0.16 and 0.39 (see Table 1).

\footnotetext{
${ }^{6}$ Eligible participants were invited with the assistance of prison educators, and only interested participants received the information and consent letter. Therefore, we are not able to estimate the percentage of eligible participants who did not take part in the study. Additional sociodemographic information regarding the participants may be obtained upon request from the corresponding author.
}

\subsection{Self-report psychopathy-short form (SRP-SF; Paulhus et al., 2016)}

The SRP-SF was used to assess psychopathic traits. The SRP-SF is a self-report questionnaire modeled after the PCL-R (Hare, 2003) and consists of 29 items rated on a 5-point Likert scale. Prior studies have provided extensive support for the four-factor structure of the SRP-SF, as well as good reliability and construct validity across different populations (Gordts, Uzieblo, Neumann, Van den Bussche, \& Rossi, 2015; Neal \& Sellbom, 2012; Neumann et al., 2015). In line with the PCL-R (Hare, 2003), the SRP-SF yields score on four facets: Interpersonal, Affective, Lifestyle, and Antisocial. For modeling purposes, only 7 of the 8 items making up the Antisocial factor were used, due to limited variability in scores on item 2 (i.e., "been in a delinquent gang"). Items are averaged to produce scores on each facet as well as the SRP-SF total score, with greater scores indicating higher levels of psychopathic traits. With the publication of the SRP Manual (Paulhus et al., 2016) detailed normative data are available for college, community, and offender samples. The published mean value for non-psychopathic male offenders assessed with the SRP-SF is $75.6(S D=16.2)$, and psychopathic male offenders (via PCL-R diagnosis) is $98.0(S D=16.0)$. The SRP-SF was translated into Italian for the purpose of this study. First, the SRP-SF items were independently translated by two of the authors and by two other clinical psychologists fluent in English. After a consensus on the initial translation was reached, a fifth psychologist fluent in both English and Italian and blind to the original items performed a back-translation in English. Both the translated and back-translated versions were approved by the publisher and two of the authors (R.D. Hare and C.S. Neumann) of the SRP-SF. Internal consistency in the present sample ranged between $\alpha=0.52-0.87$, with mean inter-item correlations ranging between 0.14 and 0.29 (see Table 1).

\subsection{Brief symptom inventory (BSI; Derogatis \& Melisaratos, 1983)}

The Italian version of the BSI was used as a measure of psychological distress. The BSI is a 53-item inventory derived from the widely used Symptom Checklist-90-R. Participants had to rate the severity of psychological symptoms they suffered over the past month on a 5-point Likert scale. The BSI include nine subscales (somatization, obsessivecompulsive symptoms, interpersonal sensitivity, depression, anxiety, hostility, phobic anxiety, paranoid symptoms, psychoticism) and a global index of distress (Global Severity Index; GSI), which is the mean score of all 53 items. The BSI has demonstrated good psychometric properties in both the original (Derogatis \& Melisaratos, 1983) and Italian version (Garofalo, Velotti, Crocamo, \& Carrà, 2017). We conducted a preliminary CFA and the BSI scales loaded significantly (range $=0.70$ to $0.87, p$ 's $<0.001$ ) on a single (unidimensional factor with good model fit $(\mathrm{CFI}=0.96$, RMSEA $=0.08)$.

\subsection{Data analytic approach}

Internal consistency estimates, descriptive statistics, and bivariate correlations were computed in SPSS. Concerning the first main aim of the present study, we used latent profile analysis (LPA) to identify naturally occurring DERS profiles of emotion dysregulation among participants. LPA is a person-centered approach used to cluster participants rather than variables (i.e., identify latent subgroups within the data through maximum likelihood estimation; Hallquist \& Wright, 2014), and represents an extension of Latent Class Analysis for continuous observed variables. LPA is a model-based variant of finitemixture modeling that seeks to identify nominal variables underlying the continuous data (Hallquist \& Wright, 2014; Vermunt \& Magidson, 2006). By decomposing the covariance matrix, LPA subtypes into latent classes individuals that are similar in terms of constellations of indicators (Vermunt \& Magidson, 2006). Simulation studies have shown that the Bayesian Information Criterion (BIC), and sample-size adjusted BIC are reliable indices for selecting the optimal model, with models 
Table 1

Internal consistency coefficients $(\alpha)$, means, standard deviations (SD), and bivariate associations for all study variables $(\mathrm{N}=268)$

\begin{tabular}{|c|c|c|c|c|c|c|c|c|c|c|c|c|c|c|}
\hline & & & 1. & 2. & 3. & 4. & 5. & 6. & 7. & 8. & 9. & 10. & 11. & 12. \\
\hline \multirow[t]{7}{*}{ DERS } & 1. Total & & - & & & & & & & & & & & \\
\hline & 2. Nonacceptance & & $0.75^{* * *}$ & - & & & & & & & & & & \\
\hline & 3. Goals & & $0.71^{* * * *}$ & $0.48^{* * *}$ & - & & & & & & & & & \\
\hline & 4. Impulse & & $0.78^{* * * *}$ & $0.45^{* * *}$ & $0.49^{* * *}$ & - & & & & & & & & \\
\hline & 5. Awareness & & $0.29^{* * * *}$ & -0.12 & 0.06 & $0.16^{* *}$ & - & & & & & & & \\
\hline & 6. Strategies & & $0.86^{* * * *}$ & $0.69^{* * *}$ & $0.52^{\text {**:** }}$ & $0.58^{* * * *}$ & 0.05 & - & & & & & & \\
\hline & 7. Clarity & & $0.65^{\text {**** }}$ & $0.37^{* * *}$ & $0.39^{\text {**** }}$ & $0.41^{* * * *}$ & $0.21^{\text {***** }}$ & $0.48^{* * * *}$ & - & & & & & \\
\hline \multirow[t]{9}{*}{ SRP-SF } & 8. Total & & $0.34^{* * * *}$ & 0.09 & $0.22^{* * *}$ & $0.43^{* * *}$ & $0.25^{\text {***** }}$ & $0.20^{* * *}$ & $0.35^{* * * *}$ & - & & & & \\
\hline & 9. Interpersonal & & $0.20^{* *}$ & 0.02 & 0.09 & $0.26^{* * *}$ & $0.20^{* * *}$ & $0.12^{* *}$ & $0.15^{*}$ & $0.83^{* * * *}$ & - & & & \\
\hline & 10. Affective & & $0.34^{\text {******* }}$ & 0.09 & $0.17^{* * *}$ & $0.39^{*: * *}$ & $0.20^{* *}$ & $0.26^{* * * *}$ & $0.26^{\text {**** }}$ & $0.68^{\text {**:*: }}$ & $0.46^{* * * *}$ & - & & \\
\hline & 11. Lifestyle & & $0.39^{* * * *}$ & $0.18^{* *}$ & $0.31^{* * * *}$ & $0.46^{* * *}$ & $0.19^{* *}$ & $0.23^{* * * *}$ & $0.26^{* * * *}$ & $0.85^{* * *}$ & $0.59^{* * * *}$ & $0.47^{* * * *}$ & - & \\
\hline & 12. Antisocial & & $0.19^{* *}$ & 0.01 & $0.13^{*}$ & $0.28^{* * *}$ & $0.19^{* *}$ & 0.06 & $0.15^{*}$ & $0.83^{* * * *}$ & $0.58^{* * * *}$ & $0.35^{* * * *}$ & $0.63^{* * *}$ & - \\
\hline & & $\alpha$ & 0.88 & 0.75 & 0.67 & 0.79 & 0.52 & 0.80 & 0.51 & 0.87 & 0.74 & 0.52 & 0.67 & 0.67 \\
\hline & & $M I C$ & 0.18 & 0.34 & 0.30 & 0.39 & 0.16 & 0.33 & 0.17 & 0.19 & 0.29 & 0.14 & 0.23 & 0.21 \\
\hline & & $M$ & 81.54 & 14.75 & 13.07 & 13.20 & 14.08 & 16.52 & 9.86 & 73.01 & 17.08 & 17.69 & 19.27 & 15.69 \\
\hline & & $(S D)$ & (20.04) & (5.50) & (4.25) & (5.29) & (4.23) & (6.21) & (3.42) & (18.46) & (5.90) & (4.87) & (5.79) & (6.26) \\
\hline
\end{tabular}

Note. DERS = Difficulties in Emotion Regulation Scale. SRP-SF = Self-Report Psychopathy-Short Form.

$* p<.05$.

** $p<.01$

*** $p<.001$.

having lower BIC values being preferred (Nylund, Asparoutiov, \& Muthen, 2007). Further, the Lo-Mendel-Rubin (LMR) likelihood difference tests the fit between two nested models that differ by one class. A significant LMR $p$-value indicates that a model fits the data significantly better than the model with one less class, whereas a nonsignificant LMR test for $k$ classes indicates that the $k$ - 1 class solution is a better model. Theoretical coherence and classification accuracy of the obtained subtypes are also a useful guide for deciding on optimal number of classes. Viable LPA solutions are obtained when the average latent class probabilities for the most likely class membership are 0.80 or greater (Vermunt \& Magidson, 2006). To validate DERS subtypes, primary analyses involved a series of planned comparisons (one-way ANOVAs) on SRP-SF scores between the DERS subtypes emerged from the LPA.

For the second aim of the study, we examined variable-centered associations between latent psychopathy and emotion dysregulation factors, while accounting for psychological distress. Structural equation modeling (SEM) using robust weighted least squares estimation procedure was employed. SEM is a rigorous statistical method for understanding the latent variable dimensions of the measures examined as well as their associations. The advantages of SEM over classical test theory include modeling error separately from common variance, specification of unambiguous item-to-factor relations, and providing robust evidence of construct validity (Strauss \& Smith, 2009). In addition, SEM provides a method for addressing highly correlated variables (i.e., potential problems of multi-collinearity) by using them as indicators of an underlying latent variable (factor), and thus provides an advantage over the traditional (manifest variable) multiple regression approach. An initial CFA was conducted to test the four-factor model of the Italian version of the SRP-SF (Hare \& Neumann, 2008), given it had not been previously tested in Italian offender samples. We also ran a CFA with the SRP-SF facets in conjunction with the higher-order DERS factor to examine how psychopathy facets correlated with a broad emotion dysregulation factor. To assess model fit, a two-index strategy was adopted (Hu \& Bentler, 1999), using the incremental Comparative Fit Index (CFI) and the absolute Root Mean Square Error of Approximation (RMSEA) index. We relied on the traditional CFI $\geq 0.90$ and RMSEA $\leq 0.08$ as indicative of acceptable model fit to avoid falsely rejecting viable latent variable models, given that model complexity increases the difficulty of achieving more conservative levels of model fit (West, Taylor, \& Wu, 2012). Lastly, an SEM was specified to examine how the superordinate SRP-SF factor was predicted by both the DERS and psychological distress (BSI) factors. In this way, we could determine if emotion dysregulation had incremental predictive validity in predicting psychopathic traits, above and beyond distress.

\section{Results}

Internal consistency estimates, descriptive statistics, and manifestvariable bivariate associations between SRP-SF facets and DERS scales are reported in Table 1. Based on SRP Manual norms for offenders (Paulhus et al., 2016), the mean SRP-SF total score for the current sample was generally consistent with what is seen in male offenders from North American. The SRP Manual indicates that a total SRP-SF score of 94-95 for offenders represents elevated psychopathic traits. Using a total score of 95 , there were $14.2 \%$ of cases reporting elevated psychopathic traits. Inspection of the correlation matrix revealed widespread positive significant associations between DERS total and scale scores and SRP-SF total and scale scores, mostly with small-tomoderate magnitude. With few exceptions, the correlation pattern highlighted that psychopathic traits were positive related to difficulties in emotion regulation.

\subsection{Latent profile analysis of emotion dysregulation dimensions and associations with psychopathic traits}

As shown in Table 2, the LPA results indicated that a 3-class solution was best, with the LMR test becoming non-significant for the 4-class solution, along with modest changes in BIC. The average latent class assignment probabilities for the 3-class model suggested a high degree of class differentiation, ranging between 0.94 and 0.99 for most likely class membership.

The three latent classes are graphically summarized in Fig. 1. Rather

Table 2

Latent profile analysis results: model fit indices for one- to four-class solutions

\begin{tabular}{lllllll}
\hline Model & $\mathrm{P}$ & $\mathrm{LL}$ & $\mathrm{BIC}$ & $\mathrm{BIC}_{\mathrm{adj}}$ & $\mathrm{LMR} p$ & Classification accuracy \\
\hline 1-class & 12 & -1894.71 & 3856.52 & 3818.48 & - & - \\
2-class & 19 & -1716.19 & 3538.61 & 3478.37 & 0.000 & $0.94-0.96$ \\
3-class & $\mathbf{2 6}$ & $\mathbf{- 1 6 6 1 . 1 6}$ & $\mathbf{3 4 6 7 . 6 9}$ & $\mathbf{3 3 8 5 . 2 6}$ & $\mathbf{0 . 0 0 3}$ & $\mathbf{0 . 9 4 - 0 . 9 9}$ \\
4-class & 33 & -1628.38 & 3441.26 & 3336.63 & 0.206 & $0.84-0.92$
\end{tabular}

Note. $\mathrm{P}=$ number of free parameters; $\mathrm{LL}=$ log-likelihood; $\mathrm{BIC}=$ Bayesian information criteria; $\mathrm{BIC}_{\mathrm{adj}}=$ adjusted BIC; LMR $p=p$-value of the Lo-MendellRubin adjusted ratio test for $\mathrm{k}$ versus $k$ - 1 class solution (low p-value rejects $k$ - 1 model in favor of $k$ class model). Best fitting model indices in bold. 


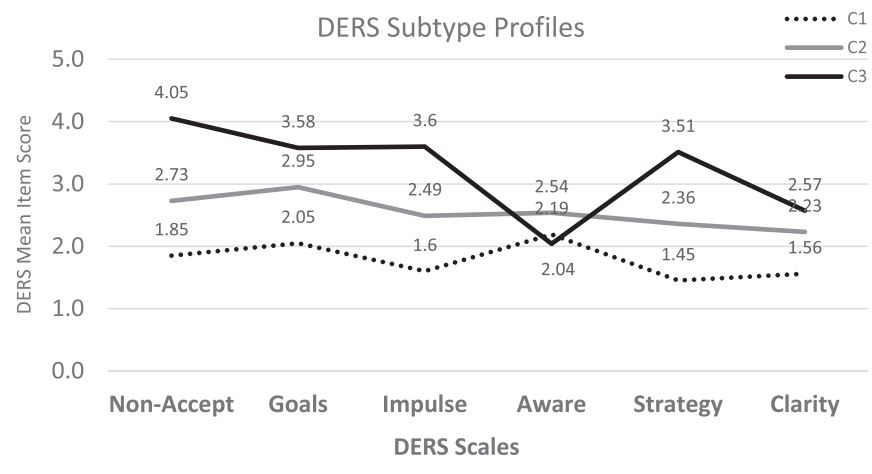

Fig. 1. Latent subtype profiles: Mean item DERS scale scores.

than by different subtypes characterized by unique profiles, the DERS subgroups were characterized by uniformly low (C1; $N=116 ; 43.3 \%)$, medium (C2; $N=130 ; 48.5 \%$ ), or high levels (C3; $N=22 ; 8.2 \%$ ) of emotion dysregulation, and thus did not appear to reflect subtypes with distinct profiles, but more so subgroups which differed in degree of emotion dysregulation, bearing support to the dimensional nature of emotion dysregulation across domains. The only exception was that there was little differentiation of the subtypes on the Awareness scale. This latent profile solution is consistent with the strong latent correlations typically found among the DERS first-order factors, as well as our current CFA results of a single unidimensional DERS model (see below). Thus, the current and previous finding highlight that each DERS scale domain reflects different manifestations of a broad difficulty in emotion regulation (John \& Eng, 2014). Further, the fact that the DERS Awareness scales did not show the same pattern of the other DERS subscales is consistent with an increasing number of studies indicating that the Awareness scale contributes minimally to the overall DERS model (John \& Eng, 2014).

Next, we validated the DERS subgroups based on individual scores on psychopathic traits, using planned ANOVA comparisons. As shown in Table 3, the C3 subgroup (higher emotion dysregulation) reported greater psychopathy affective scores than the $\mathrm{C} 2$ and the $\mathrm{C} 1$ (lower emotion dysregulation) subgroups. The results in Table 3 also show that the C3 subgroup reported significantly higher lifestyle and SRP-SF total scores than the C1 subgroup. As further evidence of the linearity between SRP and DERS scores, the C2 subgroup (moderate emotion dysregulation) also differed from $\mathrm{C} 1$ with respect to the affective, lifestyle, and SRP-SF total scores. Finally, the C2 subgroup reported significantly higher interpersonal psychopathy traits, compared to the C1 subgroup. As reported in Table 3, effect sizes for group comparisons were small-to-moderate in magnitude.

\subsection{Modeling associations between psychopathy and emotion dysregulation}

\subsubsection{CFA results}

The CFA results indicated acceptable fit for the 4-factor model of the Italian SRP-SF items $(\mathrm{CFI}=0.90$, RMSEA $=0.06$ ). All factor loadings were significant and the factors were strongly inter-correlated ( $p$ 's < 0.05-0.001). See Supplemental Fig. 1 for details. We also ran a CFA with the four psychopathy factors and a superordinate DERS factor, which showed good fit (CFI $=0.90$, RMSEA $=0.05$ ). As expected, modeling measurement error separately from common variance, the latent psychopathy factors showed an increased association ( $p$ 's < 0.003-0.0001) with the DERS superordinate factor, $r^{\prime} s=0.20-0.23$ (antisocial, interpersonal) and $r^{\prime} s=0.49-0.50$ (affective, lifestyle), compared to the manifest-variable correlations between the SRP-SF scales and DERS total (cfr. Table 1).

\subsubsection{SEM results}

Given the strong latent correlations between SRP-SF factors, we set the four (first-order) factors to load on a super-ordinate factor, and to represent the syndrome of psychopathy (Neumann et al., 2007). The super-ordinate psychopathy factor was set to be predicted by the DERS factor, while controlling for the psychological distress (BSI) factor. This model included the SRP-SF items as indicators for their respective factors, along with the DERS and the BSI subscales as indicators for their respective emotion dysregulation and psychological distress factor. The a-priori choice of focusing on the DERS super-ordinate factor, rather than on the subscales, was driven by accumulating evidence that the DERS subscales have weak discriminant validity and may be more accurately represent reflections of broader emotion dysregulation. This choice was also consistent with the results of LPA analysis. The SEM parameters are displayed in Fig. 2. The SEM results revealed that the psychopathy factor was significantly predicted of both the DERS $(0.20)$ and the BSI $(0.25)$ factors $(p ' s<0.001)$, and thus, the DERS factor displayed incremental validity above and beyond the distress factor. The BSI and DERS factors were strongly correlated with each other $(r=0.67, p<.001)$. This SEM accounted for $16 \%$ of the variance in the psychopathy factor.

\section{Discussion}

To our knowledge, this is among the first studies to employ an emotion regulation framework to understand psychopathic traits combining latent person- and variable-centered methods. As such, the present study offers new insights and methodological approaches for examining the role of emotion dysregulation in psychopathic personality. Findings provided evidence that psychopathy is positively linked with emotion dysregulation among violent male offenders. The association between psychopathic traits and emotion dysregulation was not accounted for by levels of psychological distress. Critically, the

Table 3

Latent class validation: DERS subgroups means (SDs) and differences on psychopathy (SRP-F) facet and total scores

\begin{tabular}{|c|c|c|c|c|c|c|}
\hline & Low DERS & Medium DERS & High DERS & & & \\
\hline Variable & Class 1 (C1) & Class 2 (C2) & Class 3 (C3) & C1 vs C2 & C1 vs C3 & $\mathrm{C} 2$ vs $\mathrm{C} 3$ \\
\hline Self-Report Psychopathy-Short Form (SRP-SF) & & & & $\mathrm{F}(1,244)$ & $\mathrm{F}(1,136)$ & $\mathrm{F}(1,150)$ \\
\hline Interpersonal & $16.18(5.07)$ & $17.90(6.32)$ & $17.00(6.84)$ & $\begin{array}{l}5.48, p=.02 \\
\left(\eta_{p}^{2}=0.02\right)\end{array}$ & $n s$ & $n s$ \\
\hline Affective & $16.41(4.54)$ & $18.38(4.53)$ & $20.31(6.57)$ & $\begin{array}{l}11.56, p=.001 \\
\left(\eta_{p}^{2}=0.05\right)\end{array}$ & $\begin{array}{l}11.68, p=.001 \\
\left(\eta_{p}^{2}=0.08\right)\end{array}$ & $\begin{array}{l}2.96, p=.08 \\
\left(\eta_{p}^{2}=0.02\right)\end{array}$ \\
\hline Lifestyle & $17.52(5.65)$ & $20.37(5.56)$ & $22.04(5.46)$ & $\begin{array}{l}15.85, p=.000 \\
\left(\eta_{p}^{2}=0.06\right)\end{array}$ & $\begin{array}{l}11.98, p=.001 \\
\left(\eta_{p}^{2}=0.08\right)\end{array}$ & $n s$ \\
\hline Antisocial & $15.23(5.45)$ & $15.96(6.62)$ & $16.50(8.05)$ & $n s$ & $n s$ & $n s$ \\
\hline SRP-SF Total & $68.53(17.19)$ & $75.87(17.98)$ & $79.42(22.79)$ & $\begin{array}{l}10.64, p=.001 \\
\left(\eta_{p}^{2}=0.04\right)\end{array}$ & $\begin{array}{l}6.96, p=.009 \\
\left(\eta_{p}^{2}=0.05\right)\end{array}$ & $n s$ \\
\hline
\end{tabular}

Note. $\eta_{\mathrm{p}}^{2}=$ partial eta-squared, measure of effect size $(0.01=$ small effect size; $0.06=$ medium effet size; $0.14=$ large effect size; Cohen et al., 2001$)$. 


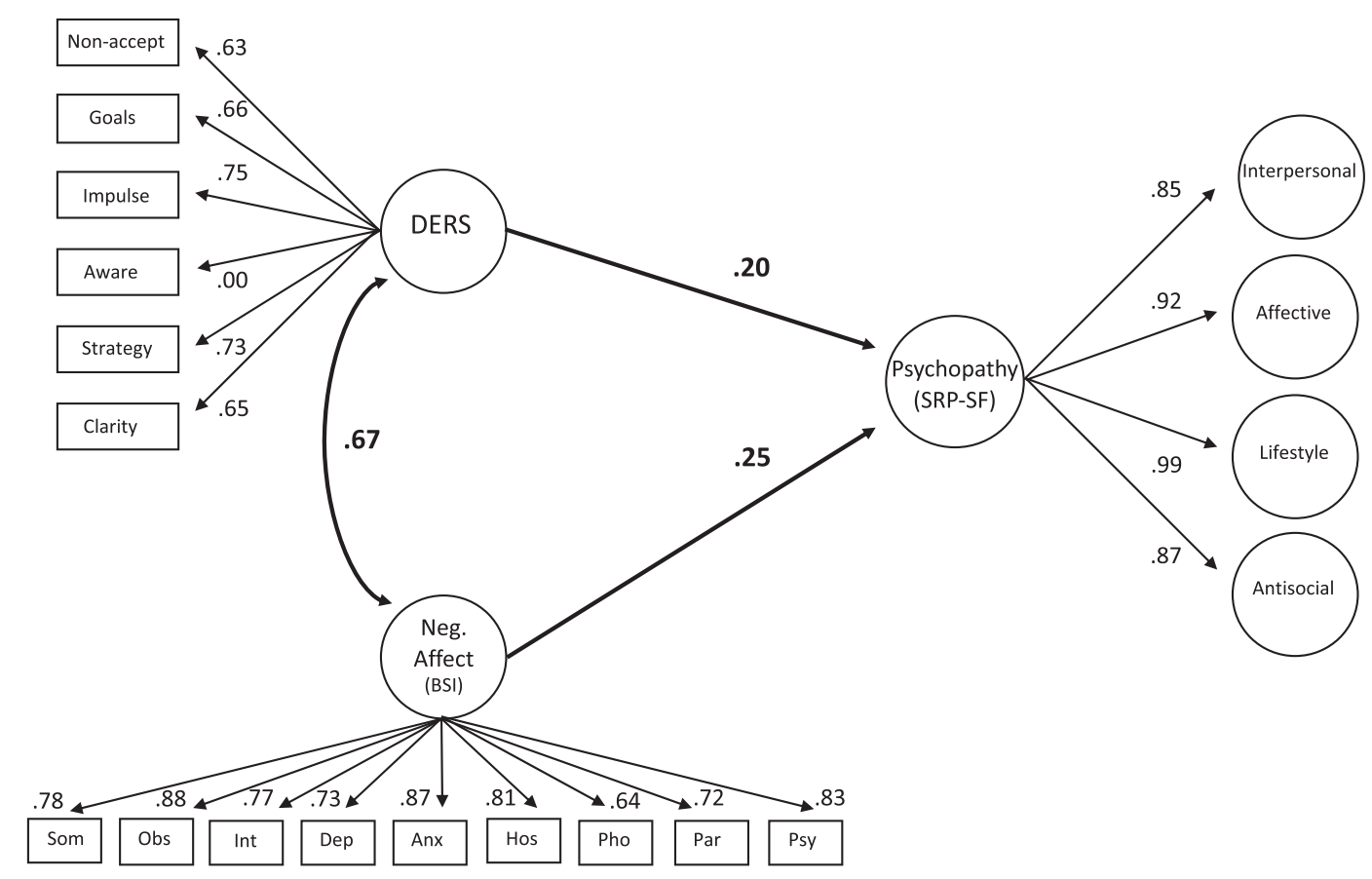

Fig. 2. SEM results with the SRP-SF super-ordinate psychopathy factor predicted by latent DERS and BSI super-ordinate factors.

subgroup with the greatest degree of emotional dysregulation also manifested the highest level of affective psychopathic features, compared to the other two subgroups. Further, our correlational findings (both manifest and latent variable) suggest that the four psychopathy factors may have different degrees of associations with emotion dysregulation, with the affective and lifestyle factors especially associated with greater emotion dysregulation.

At the same time, the correlational results showed positive associations between emotion dysregulation and psychopathic traits across facets, suggesting that there is some uniformity in the associations between greater difficulties in emotion regulation and higher levels of psychopathic propensities, consistent with some prior studies (e.g., Lishner et al., 2011; Malterer et al., 2008). The associations between psychopathic traits and emotion dysregulation involved all of the domains within in Gratz and Roemer's (2004) emotion regulation model. That is, elevations on psychopathic traits were associated with poor distress tolerance, poor behavioral control under emotional arousal (i.e., negative urgency), poor attention and awareness for emotions, limited emotion regulation strategies, and poor emotional clarity. Accordingly, the latent variable CFA results revealed significant associations between the four psychopathy factors and a broad emotion dysregulation factor. Although impairments in these domains of emotion regulation have clear conceptual overlap with the behavioral traits of psychopathy (i.e., disinhibition, aggression), their relevance for affective traits of psychopathy have not been extensively examined. The current results challenge traditional conceptualizations that core affective features of psychopathy simply reflect unemotionality, and instead suggest, to some degree, that they also involve affective dysregulation.

From a person-centered perspective, the LPAs conducted with the six emotion dysregulation dimensions indicated that a 3-class solution provided the most parsimonious model with high classification accuracy. Rather than finding evidence of unique patterns of profiles (i.e., distinct subtypes) of emotion dysregulation (e.g., elevation on some but not other scales of the DERS), as proposed by the DERS model (Gratz \& Roemer, 2004), individuals were more aptly classified (grouped) based on the severity of impairments in emotion dysregulation across domains. In keeping with an increasing number of studies, as well as with our SEM analysis, this finding suggests that the DERS dimensions may represent alternative manifestations reflecting a more generalized, underlying deficit in emotion regulation - rather than truly isolated deficits in selected components (John \& Eng, 2014). Participants were therefore best grouped in terms of low, medium, or elevated emotion dysregulation across the DERS scales (except for the problematic Awareness scale). The current results are consistent with other recent LPA research conducted with a large offender sample using a different measure of emotion regulation (i.e., the Trait Meta-Mood Scale; Salovey, Mayer, Goldman, Turvey, \& Palfai, 1995), which also revealed three subgroups characterized by low, medium, and high levels of emotion regulation across domains (Garofalo, Neumann, \& Kosson, 2017). Overall, it appears that global (as opposed to specific) emotion regulation deficits may vary continuously, with subgroups showing clinically meaningful differences in terms of degree of emotion dysregulation and psychopathic traits. This pattern bears close resemblance to what is often seen in other psychopathological symptoms, which can be continuously distributed but for which it is possible to identify thresholds of clinical utility (e.g., depression; Maj, 2016).

The subgroups were validated by looking at elevations on psychopathic traits across DERS subtypes. Greater levels of emotion dysregulation were associated with higher psychopathic traits, especially affective and lifestyle traits. The most notable differentiation of the DERS subgroups was found for affective traits, with the most severe emotion dysregulation subgroup (C3) showing the highest levels of affective psychopathic features. The antisocial facet showed a similar pattern, although the differences across profiles were not statistically significant. In contrast, only the two DERS subgroups of offenders with low-to-moderate emotion dysregulation differed in terms of interpersonal psychopathy traits (moderate $>$ low). This finding suggests that, although the interpersonal traits of psychopathy may be modestly related with emotion dysregulation, from a person-centered perspective, offenders with severe emotion dysregulation may not manifest notable levels of interpersonal psychopathic features. Only in offenders with relatively more intact emotion regulation skills will there be potential elevation in interpersonal features, likely connected to better intelligence and executive functioning.

In light of the different pattern emerged for the interpersonal facet, 
there may be intriguing differential associations between the four psychopathy factors and a range of external correlates (Hare \& Neumann, 2008), which may also be consistent with different etiological pathways contributing to the affective and interpersonal traits of psychopathy (Patrick et al., 2009). Findings that offenders who reported greater difficulties in emotion regulation were also more likely to report greater levels of both affective and lifestyle traits of psychopathy expand on recent findings that negative affect and psychological distress are not exclusively linked to the behavioral components of psychopathy, but extend to the affective component of psychopathy (Benning, 2013; Colins et al., 2016; Jackson et al., 2007; Neumann \& Pardini, 2014). Taken together, it appears that the affective traits of psychopathy are related to broader emotional disturbances that include difficulties in regulating emotions. However, it should be emphasized that the four SRP domains are all inter-related in capturing the syndrome of psychopathic personality (Neumann et al., 2007), and none of them alone is sufficient to represent psychopathy (Lilienfeld et al., 2012; Lynam \& Miller, 2012).

The CFA results provided support for the adequacy of the four-factor structure of the SRP-SF in its Italian version, which adds to the considerable support for this model (Neumann et al., 2015). Subsequently, SEM analyses were conducted on the most parsimonious model which involved the use of a super-ordinate (SRP-SF) psychopathy factor (inline with research on the PCL-R; Neumann et al., 2007), and a superordinate emotion dysregulation (DERS) factor, accounting for individual differences in psychological distress, as indexed by the BSI factor. This SEM analysis revealed that greater levels of psychopathy were predicted by greater levels of psychopathological distress. After accounting for psychological distress (which was strongly associated with the DERS factor), greater levels of psychopathy were also predicted by greater difficulties in emotion regulation, in line with recent studies suggesting a general disturbance in affective functioning in psychopathic individuals (Hoppenbrouwers et al., 2016; Neumann, Johansson, \& Hare, 2013). These results showed that psychopathy, represented in terms of a broad syndrome, is positively linked with emotion dysregulation, but this link is not fully accounted for by general psychological distress.

Notably, person- and variable- centered findings were strikingly consistent, providing evidence of a positive association between psychopathic traits and difficulties in emotion regulation. As opposed to the notion that psychopathy involves deficient affective experience, our results suggest that psychopathy also involves disturbances in the ability to regulate emotions, with the largest effect sizes reported for the affective and lifestyle psychopathy domains. Rather than being redundant, evidence that the associations between psychopathic traits and emotion dysregulation are comparable from variable and personcentered perspectives increases the confidence in our findings. Future research incorporating non-self-report indices of emotion regulation is nonetheless needed to ascertain whether the different DERS profiles emerged truly reflect the presence of naturally occurring subtypes of individuals that differ qualitatively and not only quantitatively.

Corroborating and extending previous findings (Baskin-Sommers et al., 2016; Ermer et al., 2012; Long et al., 2014; Malterer et al., 2008), these results advance current knowledge suggesting that the role of emotion dysregulation in psychopathy is stronger and more specific than previously noted. In contrast with the hypothesis of the dualpathway model (Fowles \& Dindo, 2009), the associations between emotion dysregulation and psychopathic traits were not limited to the behavioral features and were not accounted for by increased levels of general psychological distress often related to externalizing psychopathology. Our findings also provide only partial support for the hypotheses of the response-modulation theory (Patterson \& Newman, 1993). As would be expected by the response-modulation theory, relations with emotion dysregulation were not limited to the behavioral traits of psychopathy but extended to its affective features. However, these relations did not involve different components of emotion dysregulation, but broader difficulties in emotion regulation across domains. Furthermore, compared to theories based on the early twofactor conceptualization of psychopathy, our findings support the utility of parsing the interpersonal and affective traits of psychopathy in separate components, especially from a person-centered perspective (Mokros et al., 2015; Neumann, Vitacco, \& Mokros, 2016).

The current findings may also have relevant implications for the management of offenders with psychopathic traits, challenging the long-held belief that psychopathic offenders should not be allocated to interventions aimed at improving emotion regulation skills. In line with recent recommendations for the treatment of violent and sexual offenders (Garofalo, Velotti, \& Zavattini, 2017; Gillespie, Mitchell, Fisher, \& Beech, 2012; Roberton et al., 2015), the current findings suggest that psychopathic offenders may also benefit from interventions targeting the awareness, understanding, and management of emotional experiences. Notably, improvements in emotion regulation in these domains may also help reduce the risk of violent re-offending associated with psychopathy.

\subsection{Limitations}

The current findings should be considered in light of the study limitations. First, we relied on self-report measures, which could have inflated covariation among study variables due to common method variance. Although both the SRP-SF and the DERS have shown strong correlations with non-self-report indices of psychopathy and emotion dysregulation, respectively, future investigations with clinician-rated assessment of psychopathy and laboratory measures of emotion regulation are warranted to examine the robustness of the current findings. Second, the cross-sectional design of the study does not allow us to speculate about the directionality of the associations between psychopathy and emotion dysregulation. Yet, current findings may stimulate longitudinal investigations on the associations between emotion dysregulation and psychopathic traits over time. Third, our sample consisted of male incarcerated violent offenders, and the generalizability of our findings to different populations requires further scrutiny. Fourth, the internal consistency coefficients of some of the scales used in this study fell below desirable limits, though of course, alpha is strongly influenced by scale length and the SRP facets and the DERS subscales are indeed very brief. However, because low internal consistency deflates correlation coefficients, the alpha coefficients of some of the scales used place our correlational results on the conservative side, rather than inflating the risk of overestimation. Moreover, the latentvariable modeling approach adopted for the main hypothesis testing allowed us to account for imperfect measurement. Finally, future studies may attempt to extend current findings by incorporating a different operationalization of psychopathy, such as the PPI and its derivatives (Lilienfeld \& Widows, 2005), or the triarchic model of psychopathy (Patrick et al., 2009).

\section{Conclusions}

The present study offers novel insight into the emotional functioning of offenders with high levels of psychopathic traits. Specifically, it appears that the emotional dysfunctions related to psychopathy may include problems with emotion regulation. Furthermore, our study suggests that difficulties in emotion regulation may not be selectively related to the behavioral component of psychopathy, but likely extend to affective traits. Overall, these findings provide preliminary evidence that an emotion regulation framework can be aptly applied to further our understanding of psychopathy, and in line with early theoretical descriptions (Albert et al., 1959), that suggest disturbances in emotion regulation could be important characteristics in relation to the psychopathy construct. Importantly, a focus on emotion dysregulation may also provide invaluable insights to refine developmental theories of psychopathy (Eisenbarth, Krammer, Edwards, Kiehl, \& Neumann, 
2018), to understand associations between psychopathic traits and maladaptive behavior, and to tailor and improve treatment interventions for offenders with psychopathic traits.

Supplementary data to this article can be found online at https:// doi.org/10.1016/j.jcrimjus.2018.05.013.

\section{References}

Albert, R. S., Brigante, T. R., \& Chase, M. (1959). The psychopathic personality: A content analysis of the concept. The Journal of General Psychology, 60(1), 17-28. http://dx. doi.org/10.1080/00221309.1959.9710204.

Aldao, A., Nolen-Hoeksema, S., \& Schweizer, S. (2010). Emotion-regulation strategies across psychopathology: A meta-analytic review. Clinical Psychology Review, 30(2), 217-237. http://dx.doi.org/10.1016/j.cpr.2009.11.004.

Ali, F., Amorim, I. S., \& Chamorro-Premuzic, T. (2009). Empathy deficits and trait emotional intelligence in psychopathy and Machiavellianism. Personality and Individual Differences, 47(7), 758-762. http://dx.doi.org/10.1016/j.paid.2009.06. 016.

Baskin-Sommers, A. R. (2017). Psychopaths have feelings: can they learn how to use them? Retrieved from https://aeon.co/ideas/psychopaths-have-feelings-can-theylearn-how-to-use-them.

Baskin-Sommers, A. R., Brazil, I. A., Ryan, J., Kohlenberg, N. J., Neumann, C. S., \& Newman, J. P. (2015). Mapping the association of global executive functioning onto diverse measures of psychopathic traits. Personality Disorders: Theory, Research, and Treatment, 6(4), 336-346. http://dx.doi.org/10.1037/per0000125.

Baskin-Sommers, A. R., Stuppy-Sullivan, A. M., \& Buckholtz, J. (2016). Psychopathic individuals exhibit but do not avoid regret during counterfactual decision making Proceedings of the National Academy of Sciences of the United States of America, 113(50), 14438-14443. http://dx.doi.org/10.1073/pnas.1609985113.

Benning, S. D. (2013). Heterogeneity in content and Psychopathies: Comment on Marcus et al. Personality Disorders: Theory Research and Treatment, 4(1), 83-84. http://dx.doi. org/10.1037/a0027451.

Benning, S. D., Patrick, C. J., Hicks, B. M., Blonigen, D. M., \& Krueger, R. F. (2003). Factor structure of the psychopathic personality inventory: Validity and implications for clinical assessment. Psychological Assessment, 15(3), 340-350. http://dx.doi.org/10. 1037/1040-3590.15.3.340.

Blair, R. J. R. (2005). Applying a cognitive neuroscience perspective to the disorder of psychopathy. Development and Psychopathology, 17(3), 865-891. http://dx.doi.org/ $10.1017 /$ s0954579405050418.

Brook, M., Brieman, C. L., \& Kosson, D. S. (2013). Emotion processing in psychopathy checklist-assessed psychopathy: A review of the literature. Clinical Psychology Review, 33(8), 979-995. http://dx.doi.org/10.1016/j.cpr.2013.07.008.

Carpenter, R. W., \& Trull, T. J. (2013). Components of emotion dysregulation in borderline personality disorder: A review. Current Psychiatry Reports, 15(1), 335. http:// dx.doi.org/10.1007/s11920-012-0335-2.

Cleckley, H. (1941/1988). The mask of sanity. St. Louis, MO: Mosby.

Colins, O. F., Fanti, K., Salekin, R. T., \& Andershed, H. (2016). Psychopathic personality in the general population: Differences and similarities across gender. Journal of Personality Disorders. http://dx.doi.org/10.1521/pedi_2016_30_237.

Cooke, D. J., Hart, S. D., Logan, C., \& Michie, C. (2012). Explicating the construct of psychopathy: Development and validation of a conceptual model, the comprehensive assessment of psychopathic personality (CAPP). International Journal of Forensic Mental Health, 11(4), 242-252. http://dx.doi.org/10.1080/14999013.2012.746759.

Davidson, R. J., Putnam, K. M., \& Larson, C. L. (2000). Dysfunction in the neural circuitry of emotion regulation - a possible prelude to violence. Science, 289(5479), 591-594. http://dx.doi.org/10.1126/science.289.5479.591.

DeLisi, M., \& Vaughn, M. G. (2014). Foundation for a temperament-based theory of antisocial behavior and criminal justice system involvement. Journal of Criminal Justice, 42(1), 10-25. http://dx.doi.org/10.1016/j.jcrimjus.2013.11.001.

Derefinko, K. J. (2015). Psychopathy and low anxiety: Meta-analytic evidence for the absence of inhibition, not affect. Journal of Personality, 83(6), 693-709. http://dx.doi. org/10.1111/jopy.12124.

Derogatis, L., \& Melisaratos, N. (1983). The brief Symtpom inventory. An introductory report. Psychological Medicine, 13(3), 595-605.

Dimaggio, G., Popolo, R., Montano, A., Velotti, P., Perrini, F., Buonocore, L., \& Salvatore, G. (2017). Emotion dysregulation, symptoms, and interpersonal problems as independent predictors of a broad range of personality disorders in an outpatient sample. Psychology and Psychotherapy: Theory, Research and Practice. http://dx.doi. org/10.1111/papt.12126.

Dixon, M. L., Thiruchselvam, R., Todd, R., \& Christoff, K. (2017). Emotion and the prefrontal cortex: An integrative review. Psychological Bulletin. http://dx.doi.org/10. 1037/bul0000096.

Donahue, J. J., McClure, K. S., \& Moon, S. M. (2014). The relationship between emotion regulation difficulties and psychopathic personality characteristics. Personality Disorders: Theory, Research, and Treatment, 5(2), 186-194. http://dx.doi.org/10. 1037/per0000025.

Eisenbarth, H., Krammer, S., Edwards, B. G., Kiehl, K. A., \& Neumann, C. S. (2018). Structural analysis of the PCL-R and relationship to BIG FIVE personality traits and parenting characteristics in an Hispanic female offender sample. Personality and Individual Differences, 129, 59-65. http://dx.doi.org/10.1016/j.paid.2018.03.015.

Ermer, E., Kahn, R. E., Salovey, P., \& Kiehl, K. A. (2012). Emotional intelligence in incarcerated men with psychopathic traits. Journal of Personality and Social Psychology, 103(1), 194-204.
Forth, A. E., Kosson, D. S., \& Hare, R. D. (2003). The hare psychopathy checklist: Youth version. Toronto, ON: Multi-Health System.

Fowles, D. C., \& Dindo, L. (2009). Temperament and psychopathy: A dual-pathway model. Current Directions in Psychological Science, 18(3), 179-183.

Frick, P. J., \& Morris, A. S. (2004). Temperament and developmental pathways to conduct problems. Journal of Clinical Child and Adolescent Psychology, 33(1), 54-68. http://dx. doi.org/10.1207/s15374424jccp3301_6.

Garofalo, C., Holden, C. J., Zeigler-Hill, V., \& Velotti, P. (2016). Understanding the connection between self-esteem and aggression: The mediating role of emotion dysregulation. Aggressive Behavior, 42(1), 3-15. http://dx.doi.org/10.1002/ab. 21601.

Garofalo, C., \& Neumann, C. S. (2018). Psychopathy and emotion regulation: Taking stock and moving forward. In M. DeLisi (Ed.). Routledge International Handbook of Psychopathy and Crime. London, UK: Routledge.

Garofalo, C., Neumann, C. S., \& Kosson, D. S. (2017). Psychopathic traits and emotion regulation. Paper presented at the 7th biennial meeting of the Society for the Scientific Study of Psychopathy (SSSP 2017). (Antwerp, BE).

Garofalo, C., \& Velotti, P. (2017). Negative emotionality and aggression in violent offenders: The moderating role of emotion dysregulation. Journal of Criminal Justice, 51, 9-16. http://dx.doi.org/10.1016/j.jcrimjus.2017.05.015.

Garofalo, C., Velotti, P., Crocamo, C., \& Carrà, G. (2017). Single and multiple clinical syndromes in incarcerated offenders: Associations with dissociative experiences and emotionality. International Journal of Offender Therapy and Comparative Criminology. http://dx.doi.org/10.1177/0306624X16682325.

Garofalo, C., Velotti, P., \& Zavattini, G. C. (2017). Emotion regulation and aggression: The incremental contribution of alexithymia, impulsivity, and emotion dysregulation facets. Psychology of Violence. http://dx.doi.org/10.1037/vio0000141.

Gillespie, S. M., Mitchell, I. J., Fisher, D., \& Beech, A. R. (2012). Treating disturbed emotional regulation in sexual offenders: The potential applications of mindful selfregulation and controlled breathing techniques. Aggression and Violent Behavior, 17(4), 333-343. http://dx.doi.org/10.1016/j.avb.2012.03.005.

Giromini, L., Velotti, P., de Campora, G., Bonalume, L., \& Zavattini, G. C. (2012). Cultural adaptation of the difficulties in emotion regulation scale: Reliability and validity of an Italian version. Journal of Clinical Psychology, 68(9), 989-1007. http://dx.doi.org/ $10.1002 / j c l p .21876$.

Gordts, S., Uzieblo, K., Neumann, C., Van den Bussche, E., \& Rossi, G. (2015). Validity of the self-report psychopathy scales (SRP-III full and short versions) in a community sample. Assessment. http://dx.doi.org/10.1177/1073191115606205.

Gratz, K. L., \& Roemer, L. (2004). Multidimensional assessment of emotion regulation and dysregulation: Development, factor structure, and initial validation of the difficulties in emotion regulation scale. Journal of Psychopathology and Behavioral Assessment, 26(1), 41-54. http://dx.doi.org/10.1023/b:joba.0000007455.08539.94.

Gratz, K. L., Rosenthal, M. Z., Tull, M. T., Lejuez, C. W., \& Gunderson, J. G. (2009). An experimental investigation of emotion dysregulation in borderline personality disorder. Personality Disorders: Theory, Research, and Treatment, 18-26. S(1) https://doi. org/10.1037/1949-2715.s.1.18.

Gross, J. J., \& Barrett, L. F. (2011). Emotion generation and emotion regulation: One or two depends on your point of view. Emotion Review, 3(1), 8-16. http://dx.doi.org/10. 1177/1754073910380974.

Hallquist, M. N., \& Wright, A. G. C. (2014). Mixture modeling methods for the assessment of normal and abnormal personality, part I: Cross-sectional models. Journal of Personality Assessment, 96(3), 256-268. http://dx.doi.org/10.1080/00223891.2013. 845201.

Hamilton, R. K. B., Racer, K. H., \& Newman, J. P. (2015). Impaired integration in psychopathy: A unified theory of psychopathic dysfunction. Psychological Review, 122(4), 770-791. http://dx.doi.org/10.1037/a0039703.

Hare, R. D. (2003). Manual for the psychopathy checklist-revised (2nd ed.). Toronto, ON: Multi-Health System.

Hare, R. D., \& Neumann, C. S. (2008). Psychopathy as a clinical and empirical construct. Annual Review of Clinical Psychology, 4, 217-246. http://dx.doi.org/10.1146/ annurev.clinpsy.3.022806.091452.

Harenski, C., \& Kiehl, K. A. (2010). Reactive aggression in psychopathy and the role of frustration: Susceptibility, experience, and control. British Journal of Psychology, 101, 6. http://dx.doi.org/10.1348/000712609X471067.

Hart, S. D., Cox, D. N., \& Hare, R. D. (1995). Manual for the hare psychopathy checklist: Screening version. Toronto, ON: Multi-Health System.

Hicks, B. M., \& Patrick, C. J. (2006). Psychopathy and negative emotionality: Analyses of suppressor effects reveal distinct relations with emotional distress, fearfulness, and anger-hostility. Journal of Abnormal Psychology, 115(2), 276-287. http://dx.doi.org/ 10.1037/0021-843x.115.2.276.

Hoppenbrouwers, S. S., Bulten, B. H., \& Brazil, I. A. (2016). Parsing fear: A reassessment of the evidence for fear deficits in psychopathy. Psychological Bulletin, 142(6), 573-600. http://dx.doi.org/10.1037/bul0000040.

Howe, J., Falkenbach, D., \& Massey, C. (2014). The relationship among psychopathy, emotional intelligence, and professional success in finance. International Journal of Forensic Mental Health, 13(4), 337-347. http://dx.doi.org/10.1080/14999013.2014. 951103.

Hu, L. T., \& Bentler, P. M. (1999). Cutoff criteria for fit indexes in covariance structure analysis: Conventional criteria versus new alternatives. Structural Equation Modeling-a Multidisciplinary Journal, 6(1), 1-55. http://dx.doi.org/10.1080/ 10705519909540118.

Jackson, R. L., Neumann, C. S., \& Vitacco, M. J. (2007). Impulsivity, anger, and psychopathy: The moderating effect of ethnicity. Journal of Personality Disorders, 21(3), 289-304. http://dx.doi.org/10.1521/pedi.2007.21.3.289.

John, O. P., \& Eng, J. (2014). Three approaches to individual differences in affect regulation: Conceptualization, measures, and findings. In J. J. Gross (Ed.). Handbook of 
emotion regulation(2nd ed.). New York, NY: The Guilford Press.

Karpman, B. (1948). The myth of the psychopathic personality. American Journal of Psychiatry, 104, 523-534.

Kosson, D. S., Vitacco, M. J., Swogger, M. T., Steuerwald, B. L., \& Gacono, C. B. (2016). Emotional experiences of the psychopath. The clinical and forensic assessment of psychopathy: A Practitioner's guide(2nd ed.). New York, NY: Routledge.

Kring, A. M., \& Sloan, D. M. (2009). Emotion regulation and psychopathology. A Transdiagnostic approach to etiology and treatment. New York, NY: Guilford Press.

Lilienfeld, S. O., Patrick, C. J., Benning, S. D., Berg, J., Sellbom, M., \& Edens, J. F. (2012). The role of fearless dominance in psychopathy: Confusions, controversies, and clarifications. Personality Disorders: Theory, Research, and Treatment, 3(3), 327-340. http://dx.doi.org/10.1037/a0026987.

Lilienfeld, S. O., \& Widows, M. (2005). Psychopathic Personality Inventory-Revised, Professional Manual. Lutz, FL: Psychological Assessment Resources.

Lishner, D. A., Swim, E. R., Hong, P. Y., \& Vitacco, M. J. (2011). Psychopathy and ability emotional intelligence: Widespread or limited association among facets? Personality and Individual Differences, 50(7), 1029-1033. http://dx.doi.org/10.1016/j.paid.2011. 01.018.

Lishner, D. A., Vitacco, M. J., Hong, P. Y., Mosley, J., Miska, K., \& Stocks, E. L. (2012) Evaluating the relation between psychopathy and affective empathy: Two preliminary studies. International Journal of Offender Therapy and Comparative Criminology, 56(8), 1161-1181. http://dx.doi.org/10.1177/0306624x11421891.

Long, K., Felton, J. W., Lilienfeld, S. O., \& Lejuez, C. W. (2014). The role of emotion regulation in the relations between psychopathy factors and impulsive and premeditated aggression. Personality Disorders: Theory, Research, and Treatment, 5(4), 390-396. http://dx.doi.org/10.1037/per0000085.

Lykken, D. T. (1995). The antisocial personalities. Hillsdale, NJ: Erlbaum.

Lynam, D. R., \& Miller, J. D. (2012). Fearless dominance and psychopathy: A response to Lilienfeld et al. Personality Disorders: Theory, Research, and Treatment, 3(3), 341-353. http://dx.doi.org/10.1037/a0028296.

Lynam, D. R., \& Widiger, T. A. (2007). Using a general model of personality to identify the basic elements of psychopathy. Journal of Personality Disorders, 21(2), 160-178. http://dx.doi.org/10.1521/pedi.2007.21.2.160.

Maj, M. (2016). The continuum of depressive states in the population and the differential diagnosis between "Normal" sadness and clinical depression. In J. C. Wakefield, \& S. Demazeux (Eds.). Sadness or Depression? (pp. 29-38). Dordrecht, NL: Springer.

Malterer, M. B., Glass, S. J., \& Newman, J. P. (2008). Psychopathy and trait emotional intelligence. Personality and Individual Differences, 44(3), 735-745. http://dx.doi.org/ 10.1016/j.paid.2007.10.007.

Miller, J. D., Dir, A., Gentile, B., Wilson, L., Pryor, L. R., \& Campbell, W. K. (2010). Searching for a vulnerable dark triad: Comparing factor 2 psychopathy, vulnerable narcissism, and borderline personality disorder. Journal of Personality, 78(5), 1529-1564. http://dx.doi.org/10.1111/j.1467-6494.2010.00660.x.

Mokros, A., Hare, R. D., Neumann, C. S., Santtila, P., Habermeyer, E., \& Nitschke, J. (2015). Variants of psychopathy in adult male offenders: A latent profile analysis. Journal of Abnormal Psychology, 124(2), 372-386. http://dx.doi.org/10.1037/ abn0000042.

Neal, T. M., \& Sellbom, M. (2012). Examining the factor structure of the hare self-report psychopathy scale. Journal of Personality Assessment, 94(3), 244-253. http://dx.doi. org/10.1080/00223891.2011.648294.

Neumann, C. S., Hare, R. D., \& Newman, J. P. (2007). The super-ordinate nature of the psychopathy checklist-revised. Journal of Personality Disorders, 21(2), 102-117. http://dx.doi.org/10.1521/pedi.2007.21.2.102.

Neumann, C. S., Hare, R. D., \& Pardini, D. A. (2015). Antisociality and the construct of psychopathy: Data from across the globe. Journal of Personality, 83(6), 678-692. http://dx.doi.org/10.1111/jopy.12127.

Neumann, C. S., Johansson, P. T., \& Hare, R. D. (2013). The psychopathy checklist-revised (PCL-R), low anxiety, and fearlessness: A structural equation modeling analysis. Personality Disorders: Theory, Research, and Treatment, 4(2), 129-137. http://dx.doi. org/10.1037/a0027886.
Neumann, C. S., \& Pardini, D. (2014). Factor structure and construct validity of the selfreport psychopathy (SRP) scale and the youth psychopathic traits inventory (YPI) in young men. Journal of Personality Disorders, 28(3), 419-433.

Neumann, C. S., Vitacco, M. J., \& Mokros, A. (2016). Using both variable-centered and person-centered approaches to understanding psychopathic personality. In C. B. Gacono (Ed.). The clinical and forensic assessment of psychopathy: A practitioner's guide (pp. 14-31). .

Nylund, K. L., Asparoutiov, T., \& Muthen, B. O. (2007). Deciding on the number of classes in latent class analysis and growth mixture modeling: A Monte Carlo simulation study. Structural Equation Modeling-a Multidisciplinary Journal, 14(4), 535-569.

Patrick, C. J., Fowles, D. C., \& Krueger, R. F. (2009). Triarchic conceptualization of psychopathy: Developmental origins of disinhibition, boldness, and meanness. Development and Psychopathology, 21(3), 913-938. http://dx.doi.org/10.1017/ S0954579409000492.

Patrick, C. J., \& Zempolich, K. A. (1998). Emotion and aggression in the psychopathic personality. Aggression and Violent Behavior, 3(4), 303-338. http://dx.doi.org/10. 1016/s1359-1789(97)00003-7.

Patterson, C. M., \& Newman, J. (1993). Reflectivity and learning from aversive events: Toward a psychological mechanism for the syndromes of disinhibition. Psychological Review, 100, 716-736.

Paulhus, D. L., Neumann, C. S., \& Hare, R. D. (2016). Manual of the hare self-report psychopathy scale. Toronto, ON: Multi-Health Systems.

Roberton, T., Daffern, M., \& Bucks, R. S. (2015). Beyond anger control: Difficulty attending to emotions also predicts aggression in offenders. Psychology of Violence, 5(1), 74-83. http://dx.doi.org/10.1037/a0037214.

Salekin, R. T., Neumann, C. S., Leistico, A. M., \& Zalot, A. A. (2004). Psychopathy in youth and intelligence: An investigation of Cleckley's hypothesis. Journal of Clinical Child and Adolescent Psychology, 33(4), 731-742. http://dx.doi.org/10.1207/ s15374424jccp3304_8.

Salovey, P., Mayer, J. D., Goldman, S. L., Turvey, C., \& Palfai, T. (1995). Emotional attention, clarity and repair: Exploring emotional intelligence using the trait metamood scale. In J. Pennebaker (Ed.). Emotion, disclosure and health (pp. 25-154). Washington, DC: American Psychological Association.

Strauss, M., \& Smith, G. (2009). Construct validity: Advances in methodology. Annual Review of Clinical Psychology, 5, 1-25.

Tamir, M. (2011). The maturing field of emotion regulation. Emotion Review, 3(1), 3-7. http://dx.doi.org/10.1177/1754073910388685.

Vermunt, J. K., \& Magidson, J. (2006). Latent class cluster analysis. In J. A. Hagenaars, \& A. L. MCCutcheon (Eds.). Applied latent class analysis (pp. 89-106). New York, NY: Cambridge University Press.

Vidal, S., Skeem, J., \& Camp, J. (2010). Emotional intelligence: Painting different paths for low-anxious and high-anxious psychopathic variants. Law and Human Behavior, 34(2), 150-163. http://dx.doi.org/10.1007/s10979-009-9175-y.

Visser, B. A., Bay, D., Cook, G. L., \& Myburgh, J. (2010). Psychopathic and antisocial, but not emotionally intelligent. Personality and Individual Differences, 48(5), 644-648. http://dx.doi.org/10.1016/j.paid.2010.01.003.

Vitacco, M. J., Neumann, C. S., \& Wodushek, T. (2008). Differential associations between the dimensions of psychopathy and intelligence. Replication with adult jail inmates. Criminal Justice and Behavior, 35(1), 48-55.

Vitale, J. E., \& Newman, J. P. (2009). Psychopathic violence: A cognitive-attention perspective. In M. McMurran, \& R. Howard (Eds.). Personality, personality disorder, and violence (pp. 247-264). Chichester, UK: Wiley-Blackwell.

Watts, A. L., Salekin, R. T., Harrison, N., Clark, A., Waldman, I. D., Vitacco, M. J., \& Lilienfeld, S. O. (2016). Psychopathy: Relations with three conceptions of intelligence. Personality Disorders: Theory, Research, and Treatment. http://dx.doi.org/ 10.1037 /per0000183.

West, S. G., Taylor, A., \& Wu, W. (2012). Model fit and model selection in structural equation modeling. In R. H. Hoyle (Ed.). Handbook of structural equation modeling (pp. 209-231). New York, NY: Guilford Press. 